\title{
Normative Design for Society and Anticipatory Technology Development: A Double Challenge for Design Research
}

\author{
Pieter E. Vermaas, Taylor Stone \\ Department of Philosophy, Delft University of Technology \\ p.e.vermaas@tudelft.nl \\ t.w.stone@tudelft.nl
}

\begin{abstract}
This paper analyzes the increasing use of design tools and methods towards societal goals, and the interrelated approach to technology development it necessitates. Specifically, we argue that design research can assist in developing an anticipatory approach to technology development, which in turn widens future design possibilities. The paper proceeds in four steps. First, a distinction is made between different approaches to normative design, contrasting a precautionary approach (in which societal goals are constraints to design) from a directive approach (in which these goals are situated as design requirements). Second, a similar distinction between two types of normative technology development is made: precautionary (in which technology is created that safeguards societal goals) and directed (in which technology is created that realizes these goals). Third, an alternative approach to technology development is presented, aimed at enabling future technologies to realize precautionary or directed normative design for societal goals, termed anticipatory normative technology development. Such an anticipatory approach is thus conceptualized as an important enabler of normative design. Fourth, questions of how design research can support normative design is explored, highlighting two key roles: design research can create methods for normative design, and it can provide tools for anticipatory normative technology development that enables future normative design. Related to the latter, design research can draw from its established knowledge and methods for driving innovation. To contextualize this analysis, a running example is used throughout: the development of autonomous vehicles for reducing light pollution. Developing the navigation and sensors of autonomous vehicles to operate in low-light conditions is shown to anticipate an emerging social and environmental goal, thus creating the possibility for future normative design innovations.
\end{abstract}

Keywords: Design for values, social design, technology development, design research 


\section{Introduction}

In recent years there has been an increasing use of the tools and methods of design towards social and environmental goals. Rejecting the perspective that design is value-neutral, and simply an instrumental tool for engineering, design has been recognized as a stand-alone approach to resolving societal goals and directing applications of technology towards the society we want - shaping products, systems, and services towards goals such as sustainability, social justice, transparent and inclusive governance, et cetera (e.g., Marzano, S., 2007; Brown, T., \& Wyatt, J., 2010). The rejected perspective is of course somewhat of a strawman, since design has had a societal focus for some time, as for instance in architectural design and the participatory tradition in engineering and product design. Still, design is increasingly recognized as a means that can do more than shaping products. Under the label of design thinking, for instance, it is utilized for creating new innovation strategies and governmental policies, and for addressing societal issues. Likewise, there has been an increasing interest in applied ethics regarding the role of design, and the possibilities of doing "ethics by design" (van den Hoven, J., 2017). Nascent sub-fields such as value-sensitive design and Responsible Research and Innovation are based on the premise that moral values can be incorporated into technological development and innovation processes (e.g., van den Hoven, J., 2013). Taken together, there is an increasing recognition that design can - and in many cases should - carry a normative weight. With this recognition, a new sense of responsibility has emerged to conceptualize this normative drive within design research.

In this paper we consider this application of normative design, and analyze it in the broader context of guiding technology development towards identified social and environmental goals. ${ }^{1}$ We further distinguish between normative design (referring to practice and application) and normative technology development (referring to efforts to develop technology in morally desirable directions). These are linked by a relation of support, as normative technology development enables normative design. We argue that this relation of support calls for broadening efforts in normative technology development to what we will call anticipatory normative technology development: creating technologies that enable future safeguarding or realizing of societal goals. This anticipatory form of normative technology development resembles technology development that is part of design methods for innovation (e.g., Verganti, R., 2009; Hekkert, P., \& Van Dijk, M., 2011; Bucolo, S., Wrigley, C., \& Matthews, J., 2012). Hence, design research can contribute in a double way to designing for societal goals: by improving normative design itself and by advancing supporting efforts of anticipatory normative technology development.

The next section provides a broad characterization of normative design. In section 3 we move to characterizing normative technology development. In section 4 we analyze the relation between normative design and technology development, and argue for the relevance of anticipatory normative technology development. In section 5 we further explore the anticipatory approach to technology development and relate it to design research. For giving content to this analysis, we use the design of autonomous vehicles for reducing light pollution as an example (Stone, T., Santoni de Sio, F., \& Vermaas, P. E., 2020). The delineation of normative design builds on an earlier study on the need for transparency in design for societal issues (Vermaas, P., 2019).

\footnotetext{
${ }^{1}$ For ease of writing we henceforth subsume environmental goals under societal goals.
} 


\section{Normative design}

Calls within design research to start applying design towards societal goals include the ones by Stefano Marzano (2007) and by Tim Brown and Jocelyn Wyatt (2010). Marzano expressed in his call a special responsibility of designers, since it is designers who shape many products. Outside of design one can find similar arguments. Philosophers of technology, for instance, have excelled in analyses of how technology and design choices affect society, at least since Langdon Winner (1980) argued that artifacts can embody political goals. It was later recognized that this analytic assessment can also be put to constructive ends, helping to shape products in morally desirable directions (e.g., Van den Hoven, J., 2013). Hence, one can increasingly witness various efforts aimed at designing for society, sometimes pooling the resources of engineering, architecture, design, and philosophy, as in the Delft Design for Values institute of our home university. ${ }^{2}$

Normative design comes in different forms. It may be focused on making products that foster moral and social values, such as in value-sensitive design (e.g., Friedman, B., Kahn, P. H., Jr., \& Borning, A., 2006) and design for values (e.g., Van den Hoven, J., Vermaas, P. E., \& Van de Poel, I., 2015). Similarly, it may be aimed at addressing societal goals more directly by design, such as in social design (e.g., Marzano, S., 2007; Tromp, N., \& Hekkert, P., 2019), nudging (e.g., Thaler, R. H., \& Sunstein, C. R., 2008) and positive design (e.g., Desmet, P. M. A., \& Pohlmeyer, A. E., 2013).

When thinking about the relation between normative design and the development of technology, a distinction can be made between two types of normative design. In the first type moral and social values and targets are adopted as constraints in design projects. In the second type of normative design they are articulated as requirements (Stone, T., et al., 2020). If moral and social values or targets are adopted as constraints, then designers should explore whether newly designed products could violate or come into conflict with identified values or targets, and then adjust the designs such that these conflicts are avoided. The value-sensitive design method developed by Batya Friedman and colleagues follows in part this more constraintoriented approach (e.g., Friedman, B., et al., 2006). By this method designers should actively determine - using tools such as conceptual exploration and interviews - what values of stakeholders, society, and the environment are possibly involved in a design. And with this determination, designers can improve the design such that these values are not negatively affected. We call this precautionary normative design. Alternatively, values and targets can be articulated as requirements within the design process, alongside functional requirements. In this way, moral and social values and targets are not only constraints against which designs should be checked, but also goals that immediately co-define the product under development. The design for values approach (Van den Hoven, J., et al., 2015) is an example of this second type, as it is aimed at realizing specific moral and social values through design. Similarly, social design, nudging, and positive design are instances of this second type of normative design. We call this second type directive normative design.

To illustrate this point, consider the proposal to incorporate the goal of reducing light pollution into the design of autonomous vehicles. Stone, et al. (2020) explored the possibilities of applying directive normative design to autonomous vehicles beyond the current discourse on rare "trolley-problem like" life-and-death scenarios. One societal goal that can be partly

\footnotetext{
${ }^{2}$ www.delftdesignforvalues.nl
} 
addressed via autonomous vehicles is the problem of light pollution at night. ${ }^{3}$ If autonomous vehicles are sophisticated enough to drive fully autonomous on highways and other areas dedicated only to such vehicles, it becomes feasible to switch of the lights at night on both autonomous vehicles and the road infrastructure they use. Highways through urban, rural, and natural areas can then be darkened, as well as parking areas around, for example, shopping malls and airports. These prospective ideas of "darkened highways" or "dark parking" would count as directive normative design, as is would incorporate the goal of reducing light pollution into the development of autonomous vehicles. Designing these vehicles for values such as safety counts as precautionary normative design, since the aim is then that autonomous vehicles should observe existing safety regulations and not bring new risks to other stakeholders in the public space.

Designing autonomous vehicles for "driving in the dark" is at this point still a somewhat academic possibility, since autonomous vehicles are far from generally available. Hence, a design process that would create autonomous vehicles that drive without lights and over dark roads is something for the future. Yet, one of the reasons for detailing this example was to point out that this future possibility depends on current choices. It depends, for instance, on the type of sensors that are developed for such vehicles. If sensors are developed that require the presence of sufficient light in the frequency spectrum of natural daylight, then utilizing autonomous vehicles to create darker nights becomes less likely to be realized. Yet, if a choice is made now to develop other types of sensors, this project remains a realistic possibility in the future. This brings us to the development of technology for societal goals, which is the topic of next section.

\section{Normative technology development}

The distinction between adopting societal goals as constraints or as requirements can also be drawn for the development of technologies. Regularly technologies are developed for specific societal goals. Historically this may have been rulers and states investing in new military and economic possibilities, such as weaponry, shipping, and mining. Closer to our times one may think of investments in medical care and infrastructure. More current examples can be found in the sustainable energy sector such as the development of economically viable technologies of nuclear fission and photovoltaic solar cells. And contemporary cases are efforts in research and innovation to realizing the Sustainable Development Goals as set by the United Nations, as now regularly supported by national, European, and private funding agencies. Let us call these efforts of technology development for realizing specific moral and social values and targets directed normative technology development.

Types of technology development that fall outside of this category would be technology development for the sake of technology itself, technology development for only commercial aims, and technology development for personal goals. Specifically, the first two types of technology development have been conceptualized in philosophy of technology as

\footnotetext{
${ }^{3}$ Light pollution - a summative concept to define and categorize the negative affects of artificial light at night has been shown to cause far-reaching negative effects. This includes energy usage and economic costs, ecological damage, impacts on human health, and cutting off experiences of the night sky (e.g., Stone, T., 2017). This has, in turn, led to calls to re-think how and why we light our world at night (e.g., Kyba, C., Hänel, A., \& Hölker, F., 2014). While current efforts are justifiably geared towards policy and design choices related to outdoor illumination, another avenue we propose is to consider how interrelated innovations - such as autonomous vehicles - may also be seen as a means to realize a reduction to the adverse effects of light pollution.
} 
deterministic technology development that is guided by internal and/or market forces rather than by social or democratic aims. Attempts to get this deterministic development of technology (back) under control by imposing constraints to research, innovation, and exploitation of technology may now be taken as precautionary normative technology development. Technology Assessment as envisioned after World War II (e.g., Banta, D., 2009) cannot count as an example of such normative technology development. It aimed at predicting in advance what the impact of new technologies would be, for informing policy makers and society. But Technology Assessment was not necessarily involving changing the technology development itself. The later version of Constructive Technology Assessment (Rip, A., Misa, T., \& Schot, J., 1995) comes closer to an example. In Constructive Technology Assessment the prediction of the impact of a technology became an effort that was done in parallel to the development of the technology, with interactions between the researchers working on the technology and working on the predictions. The aim was that the predictions would have an immediate impact on how the technology was actually developed. A clear and contemporary example of precautionary normative technology development is Responsible Research and Innovation (Stilgoe, J., Owen, R., \& Macnaghten, P., 2013; Von Schomberg, R., \& Hankins, J., 2019). Consider, for instance, the Horizion2020 programme of the European Commission. Researchers in that programme are involved in Responsible Research and Innovation when they are collaborating with stakeholders in society to "align" the technologies with the "values, needs and expectations of society": ${ }^{4}$

Responsible Research and Innovation (RRI) implies that societal actors (researchers, citizens, policy makers, business, third sector organisations, etc.) work together during the whole research and innovation process in order to better align both the process and its outcomes with the values, needs and expectations of society.

One could argue that Responsible Research and Innovation, when done full-heartily and with full participation of the societal stakeholders, becomes more directive normative technology development. Yet Responsible Research and Innovation does not require pre-set values or targets, and aligning may in practice mean that the development of the technology is adjusted to not violate the values of the stakeholders.

To return to our example of autonomous vehicles and light pollution, researchers at the Delft University of Technology are working to develop software and technology by which autonomous vehicles can detect pedestrians and cyclists, and predict how they will behave (e.g., Braun, M., et al., 2019). Such technology development is motivated by broadening the application domain of autonomous vehicles, but also aimed at keeping cities like Delft safe for pedestrians and its many cyclists. This technology development is thus in part motivated by the social value of inclusivity of public space, hence can count as directive normative technology development. However, the general push for autonomous vehicles to avoid traffic accidents can be positioned as precautionary normative technology development. Society has invested heavily in measures that make road traffic safer, and the development of autonomous vehicles should align to this target by being safer than traditional cars and not introducing new risks.

One can now raise the question of whether there are more types of normative technology development than precautionary and directive development. In the next section we look at the

\footnotetext{
${ }^{4}$ https://ec.europa.eu/programmes/horizon2020/en/h2020-section/responsible-research-innovation
} 
relation between normative technology development and normative design, and propose a third type.

\section{Normative design and normative technology development}

The precautionary-directive distinction introduced above leads to four types of normative design and technology development as ordered in Table 1. This ordering suggests a simple linear relation of support between research and design: precautionary normative technology developed for safeguarding specific societal goals is meant to enable precautionary normative design for those goals; and directive normative technology developed for realizing specific societal goals is meant to enable directive normative design. Although these supporting relations may hold, they are certainly not exhaustive. Normative design can draw from all available technologies, hence precautionary normative technology can at occasions also support directive design, and vice versa.

Table 1. Four types of normative design and technology development.

\begin{tabular}{l|l}
$\begin{array}{l}\text { Precautionary normative } \\
\text { technology development }\end{array}$ & $\begin{array}{l}\text { Precautionary normative } \\
\text { design }\end{array}$ \\
\hline $\begin{array}{l}\text { Directive normative } \\
\text { technology development }\end{array}$ & $\begin{array}{l}\text { Directive normative } \\
\text { design }\end{array}$
\end{tabular}

In addition to these positive relations of support one can also identify negative relations between normative technology development and normative design. First, normative technology development (precautionary or directive) can turn out to be spurious, such as when these technologies are never actually applied in normative design. Second, normative design (precautionary or directive) may require technologies that are not available and that have not been developed by separate efforts to do so. By the first relation the time, energy, and resources put in the development of the technology in question have been in vain. By the second relation the possibilities of doing normative design have been limited since it can take time to normatively develop the needed technology. Further, other technologies that emerge in the meantime may, via lock-in effects, prevent that the needed technology can be developed (De Weck, O. L., Roos, D., \& Magee, C. L., 2016).

Table 2. Normative design and normative technology development.

precautionary normative design: design in which specific moral and social values and targets are constraints

directive normative design: design in which specific moral and social values and targets are design requirements

precautionary normative technology development: development of technologies that safeguard specific moral and social values and targets

directed normative technology development: development of technologies that realize specific moral and social values and targets

anticipatory normative technology development: development of technologies that enable future technologies for safeguarding or realizing specific moral and social values and targets 
For avoiding this latter limitation, we argue for a third type of normative technology development: anticipatory normative technology development. We define it as the development of technologies that enable future technologies for safeguarding or realizing specific moral and social values and targets. Anticipatory normative technology development explicitly aims to allow for the future possibility of designing for identified goals, as the technologies needed can still be developed and utilized. In Table 2 all definitions of normative design and technology development are brought together.

Let us return to the running example. The argument given by Stone et al. (2020) was that if we want to realize darker nights via the design of autonomous vehicles, then we already need to consider the pathways for developing the sensor technologies that such vehicles will use. In the future almost all vehicles will have high levels of autonomy. Hence, a design project to let them drive without nighttime lighting can reasonable be undertaken, assuming that the sensors the vehicles use do not require the presence of sufficient light in the frequency spectrum of natural daylight. This assumption will, however, not be met if current car designers decide to use sensors that do require such light and thus guide autonomous vehicles as well as their supporting road infrastructure towards a necessity of full lighting at night. In such a scenario, they would have at best a neutral impact on efforts to reduce light pollution. Hence, if we ever want to design autonomous vehicles for realizing darker nights, we should aim to avoid a reliance on sensors that require light in the frequency of natural daylight. Steering sensor technologies for autonomous vehicles towards other options is a case of anticipatory normative technology development.

Table 3 extends Table 1 by adding this third type of normative technology development to the typology. The relation between anticipatory normative technology development and normative design is a modal one: anticipatory normative technology development supports the possibility of (future) normative design.

Table 3. Five types of normative design and technology development.

\begin{tabular}{l|l}
$\begin{array}{l}\text { Precautionary normative } \\
\text { technology development }\end{array}$ & $\begin{array}{l}\text { Precautionary normative } \\
\text { design }\end{array}$ \\
\hline $\begin{array}{l}\text { Anticipatory normative } \\
\text { technology development }\end{array}$ & \\
\cline { 2 - 2 } $\begin{array}{l}\text { Directive normative } \\
\text { technology development }\end{array}$ & Directive normative \\
\end{tabular}

\section{Normative design and design research}

An anticipatory approach to technology development can profoundly extend normative design, and thus contribute to the emergence of designing as a means to improving society. We likewise believe that design research can support this extension of normative design.

Let us take as a default that normative design starts with a societal goal and identifies technologies for realizing or safeguarding this goal. Anticipatory normative technology development extends this default by broadening the choice of technologies from existing ones to possible future ones. In the running example used here, the goal is reducing light pollution and the anticipatory approach to technology development makes future autonomous vehicles 
available for realizing this societal goal. More generally this approach allows designers to think beyond the traditional confines and scope of a specific technology and explore directions for normative design in a more open way. For a given societal goal the designer can ask if a technology such as autonomous vehicles (as well as other emerging technologies) are relevant. For example, if it was agreed that noise pollution was a goal worth pursuing in urban and suburban contexts, it can be explored if and how autonomous vehicles could be shaped such that they positively contribute to this goal. Or, if aging populations is identified an a key issue (and related concerns such as social isolation), designers can research if, and how, autonomous vehicles can be developed so that they can mitigate this problem.

Conversely, an anticipatory approach to technology development can be used to explore how a given technology can impact society over time, and determine what societal goals are involved. For instance, when autonomous vehicles become available, one can imagine that the idea that they are to be used by people taking the role of 'driver' will fade away. Such a change in framing vehicles may, in turn, lead to scenarios where vehicles are delivering and collecting passengers and goods without a 'driver' being present. Such use patterns could, if taken into consideration early, serve to support the societal goal of equality by re-designing access to essential services. Cases of such areas may be rural regions or suburban areas with weaker social structures. Autonomous vehicles can then for instance collect goods from more distant destinations and bring children and adolescents to further-away schools. By these uses of autonomous vehicles, the phenomenon of food deserts (e.g., Walker, R. E., Keane, C. R., \& Burke, J. G., 2010) could be addressed and the quality of life in rural areas could be maintained. For supporting these possibilities, some anticipatory measures should be made. For enabling the transportation of children, information sharing protocols for autonomous vehicles should be designed in a manner that origin, destination, and contents of the vehicle cannot be reasonable be made visible (think for instance about the ease of kidnapping once vehicles put information about trips in the cloud). Or, that delivery of fresh food requires refrigerated storage compartments in autonomous vehicles. Thinking one step further and keeping open the possibility that autonomous vehicles evolve towards providing shared public services, the collection and delivery of goods require that housing will be designed such that docking of parcels can be realized.

We submit this short digression on the development of autonomous vehicle technology as an illustration of how anticipatory normative technology development can extend the possibilities of normative design.

A final point to highlight is that the extension of normative design via an anticipatory approach to technology development can be supported by design research. Clearly design research enables normative design by providing design methods to designing for societal goals (e.g., Friedman, B., et al., 2006; Vermaas, P. E., et al., 2015; Tromp, N., \& Hekkert, P., 2019). But we see a second way in which design research can contribute to normative design. Anticipatory normative technology development resembles, in our view, technology development that is encapsulated by design methods for innovation, such as Vision in Product Design (Hekkert, P., \& Van Dijk, M., 2011), design-driven innovation (Verganti, R., 2009) and design innovation (e.g., Bucolo, S., Wrigley, C., \& Matthews, J., 2012). For furthering these design methods research has been done into developing future scenarios and considering both technology development and (business) opportunities. Hence, design researchers have worked on tools for determining what future markets are available for a specific technology, and for providing advice about how the technology should be developed for capturing those markets. And they have worked on tools for determining for a specific market how it will evolve, and for advising 
what new technologies are needed to remain servicing that market: These tools seem in our perspective similar to tools for determining for a specific technology what societal goal it can address, and for determining for a specific societal goal how it can be addressed by a technology. Making that design research knowledge available to normative design will widen the possibilities for normative applications of design.

\section{Conclusion}

In this paper we have considered the application of design for societal goals, and analyzed it in the context of the broader development of guiding technologies in socially desirable directions. We called this normative design and normative technology development. We have argued for distinguishing two types of normative design: in precautionary normative design societal goals are adopted as constraints, whereas in directive normative design these goals are situated as requirements. We used this distinction to single out two types of normative technology development: precautionary normative technology development (aimed at technologies that safeguard societal goals), and directed normative technology development (aimed at technologies that realize societal goals). Finally, we introduced a third type of technology development, namely anticipatory normative technology development, aimed at enabling future technologies that can safeguard or realize societal goals. We argued that this third type is an important enabler of normative design, and that design research can support normative design by creating methods for normative design, as well as providing tools for anticipatory normative technology development. Design research can offer knowledge and expertise about technology development for innovation, which can widen the possibilities for the future of normative design.

\section{Acknowledgement}

We thank Filippo Santoni de Sio for fruitful discussions on normative design and its preconditions in the field of autonomous vehicles.

\section{Citations and References}

Banta, D. (2009) What is technology assessment, International Journal of Technology Assessment in Health Care, vol. 25, supplement 1, 7-9.

Braun, M., Krebs, S., Flohr, F., \& Gavrila, D. M. (2019) EuroCity Persons: A novel benchmark for person detection in traffic scenes, IEEE Transactions on Pattern Analysis and Machine Intelligence, vol. 41, no. 8, 1844-1861.

Brown, T., \& Wyatt, J. (2010) Design thinking for social innovation, Stanford Social Innovation Review, vol. 8, no. 1, 30-35.

Bucolo, S., Wrigley, C., \& Matthews, J. (2012) Gaps in organizational leadership: Linking strategic and operational activities through design-led propositions, Design Management Journal, vol. 7, no. 1, 18-28.

De Weck, O. L., Roos, D., \& Magee, C. L. (2016) Engineering systems: Meeting human needs in a complex technological world, Cambridge, MA, MIT Press.

Desmet, P. M. A., \& Pohlmeyer, A. E. (2013) Positive design: An introduction to design for subjective well-being, International Journal of Design, vol. 7, no. 3, 5-19.

Friedman, B., Kahn, P. H., Jr., \& Borning, A. (2006) Value sensitive design and information systems. In Zhang, P., \& Galletta, D. (Eds.), Human-computer interaction in management information systems: Foundations (348-372). Armonk, NY: M.E. Sharpe. 
Hekkert, P., Van Dijk, M. (2011) Vision in design: A guidebook for innovators. Amsterdam: BIS Publishers.

Kyba, C., Hänel, A., \& Hölker, F. (2014) Redefining efficiency for outdoor lighting, Energy \& Environmental Science, vol. 7, 1806-1809.

Marzano, S. (2007), Flying over Las Vegas, Koninklijke Philips Electronics NV.

Rip, A., Misa, T., \& Schot, J. (Eds.) (1995) Managing technology in society: The approach of constructive technology assessment. London: Pinter Publishers.

Stilgoe, J., Owen, R., \& Macnaghten, P. (2013) Developing a framework for responsible innovation, Research Policy, vol. 42, 1568-1580.

Stone, T. (2017) Light pollution: A case study in framing an environmental problem, Ethics, Policy \& Environment, vol. 20, no. 3, 279-293.

Stone, T., Santoni de Sio, F., \& Vermaas, P. E. (2020) Driving in the dark: Designing autonomous vehicles for reducing light pollution, Science and Engineering Ethics, vol. 26, 387-403.

Thaler, R. H., \& Sunstein, C. R. (2008) Nudge: Improving decisions about health, wealth, and happiness, New Haven, CT: Yale University Press.

Tromp, N., \& Hekkert, P. (2019) Designing for society: Products and services for a better world, London: Bloomsbury: London.

Van den Hoven, J. (2013) Value sensitive design and responsible innovation. In Owen, R., Bessant, J., \& Heintz, M. (Eds.), Responsible innovation (75-84). Chichester: Wiley.

Van den Hoven, J. (2017) The design turn in applied ethics. In Van den Hoven, J. Miller, S., \& Pogge, T. (Eds.), Designing in ethics (11-31). Cambridge: Cambridge University Press.

Van den Hoven, J., Vermaas, P. E., \& Van de Poel, I. (Eds.) (2015) Handbook of ethics, values and technological design. Dordrecht: Springer.

Verganti, R. (2009) Design driven innovation: Changing the rules of competition by radically innovating what things mean. Boston: Harvard Business Press.

Vermaas, P. (2019) Transparency in responsible design: Avoiding engineering overconfidence and supporting societal acceptance, in Proceedings of the Design Society: International Conference on Engineering Design, 1(1), 3431-3440.

Vermaas, P. E., Hekkert, P., Manders-Huits, N., \& Tromp, N. (2015) Design methods in design for values. In Van den Hoven, J., Vermaas, P. E., \& Van de Poel, I. (Eds.), Handbook of ethics, values and technological design (179-201). Dordrecht: Springer.

Von Schomberg, R., \& Hankins, J. (2019) International handbook on responsible innovation: A global resource, Cheltenham: Edward Elgar Publishing.

Walker, R. E., Keane, C. R., \& Burke, J. G. (2010) Disparities and access to healthy food in the United States: A review of food deserts literature, Health \& Place, vol. 16, 876-884.

Winner, L. (1980) Do artifacts have politics? Daedalus, vol. 109, no. 1, 121-136. 